\title{
A HISTOLOGICAL STUDY OF IDIOPATHIC AVASCULAR NECROSIS OF THE HEAD OF THE FEMUR
}

\author{
A. INOUE, K. ONO \\ From the Department of Orthopaedic Surgery, Osaka University Medical School

\begin{abstract}
We have studied the histological appearances of forty femoral heads with idiopathic avascular necrosis. The characteristic histopathological changes of recurrent necrosis were present in 83 per cent. Recurrent necrosis occurred widely after revascularisation had progressed as far as the subchondral zone. The aetiology of idiopathic avascular necrosis of the femoral head may be a chronic condition which produces repeated infarction. The deformation and incomplete revascularisation of the femoral head may be due to repeated episodes of infarction as well as to mechanical factors related to weight-bearing.
\end{abstract}

In idiopathic avascular necrosis most of the femoral heads do not become fully revascularised. The pathogenesis of this incomplete revascularisation is still uncertain, although the effect of mechanical stress on the necrosed femoral head and the anatomy of its blood supply are considered to be the principal factors.

After a histological study of Perthes' disease in man and experimental work in the dog, Inoue et al. (1976) suggested that recurrent necrosis played an important role in the pathogenesis of this disease.

In this paper we present histological evidence that incomplete revascularisation of the femoral head in idiopathic avascular necrosis may also be due to two or more episodes of infarction occurring within the head.

\section{MATERIAL AND METHODS}

Twenty-nine femoral heads and eleven biopsies from thirty-six patients with idiopathic avascular necrosis of the femoral head were available for histological study. Twenty-four of the patients were men and twelve were women. Their age at operation ranged from fourteen to sixty-five years with an average age of forty.

The specimens were fixed in 10 per cent formol-saline. decalcified and embedded in paraffin wax. Slices of 5 millimetres thickness of the femoral head were made in the coronal plane. Further sections 5 micrometres thick were stained with haematoxylin and eosin. Fifty-seven femoral head biopsies in Perthes' disease and nine femoral heads with late segmental collapse after fractures of the femoral neck were also examined histologically.

Definitions. Based upon the previous study of Perthes' disease (Inoue et al. 1976) the histological evidence of recurrent necrosis was defined

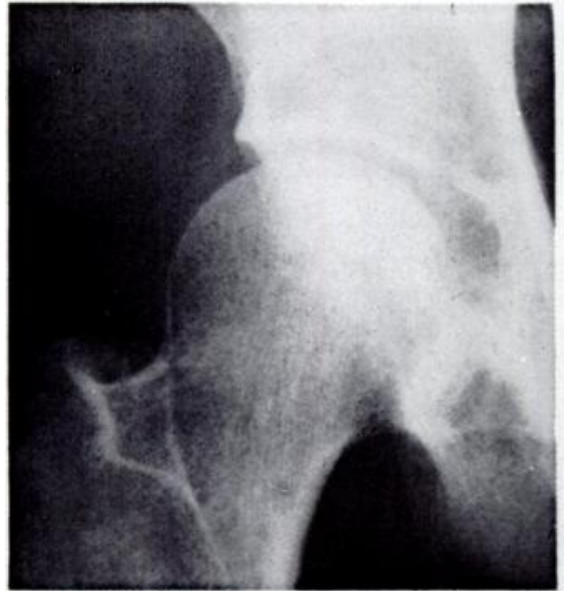

Fig. 1

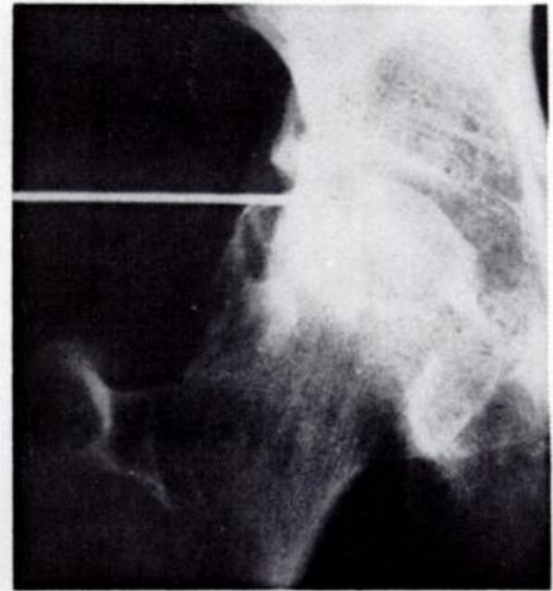

Fig. 2

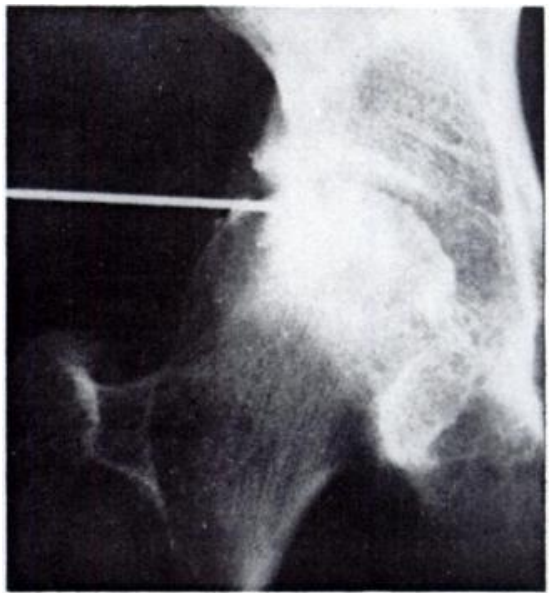

Fig. 3

Figure 1-Radiograph of a patient without symptoms or radiological changes (Stage I) but suspected of idiopathic avascular necrosis because of excessive corticosteroid administration for systemic lupus erythematosus. Figure 2-Radiograph of osteomyelography immediately after injection of contrast dye. Figure 3-Radiograph of osteomyelography, ten minutes after injection showing retention of contrast dye.

A. Inoue, M.D.
Professor K. Ono, M.D. $\}$ Department of Orthopaedic Surgery, Osaka University Medical School, Hukusima. Osaka, Japan. Requests for reprints should be sent to Dr A. Inoue. 


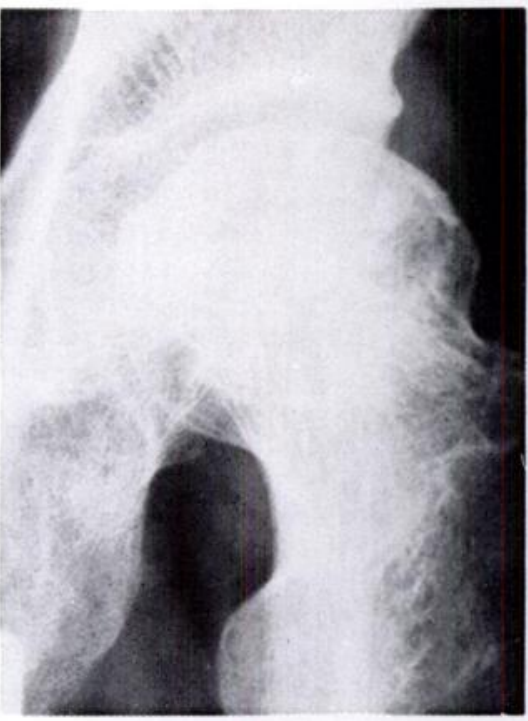

Fig. 4

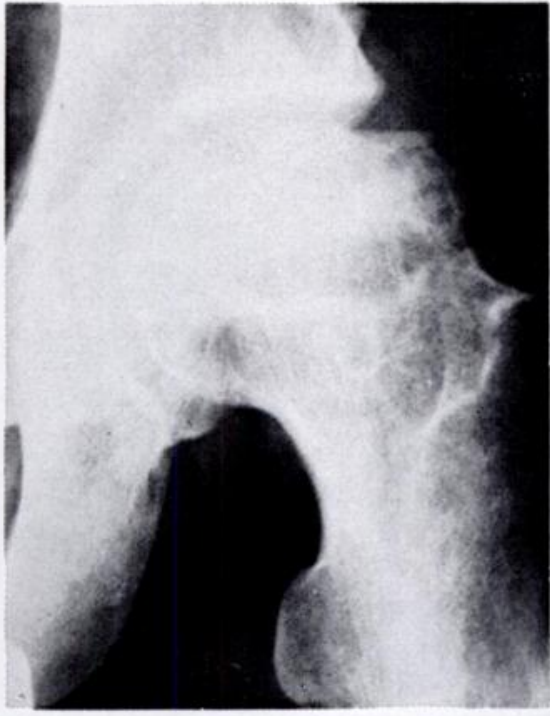

Fig. 5

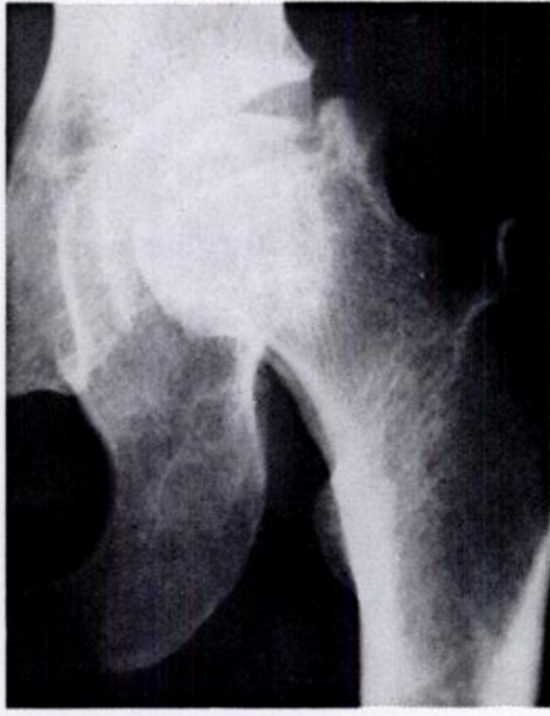

Fig. 6

Figure 4-Radiograph in Stage II showing irregular density without collapse. Figure 5-Radiograph in Stage III showing irregular density with moderate collapse. Figure 6-Radiograph in Stage IV showing severe deformity.

as the presence of dead granulation tissue with or without dead woven bone of repair.

In order to investigate the relationship between histological and radiological findings, the radiological appearances of the femoral heads at the time of operation were divided into four stages: Stage $I$, the silent stage, in which there were no symptoms and no radiological changes in the femoral head, and necrosis was diagnosed by osteomyelography (Matumoto and Mizuno 1966; Figs. 1 to 3), or by biopsy; Stage II, the initial stage, in which the radiographs showed abnormal or irregular density, with or without slight collapse (Fig. 4); Stage III, the intermediate stage, when radiographs showed irregular density with collapse (Fig. 5); Stage $I V$, the advanced stage, when severe deformity of the head was present, with or without secondary osteoarthritic change (Fig. 6).

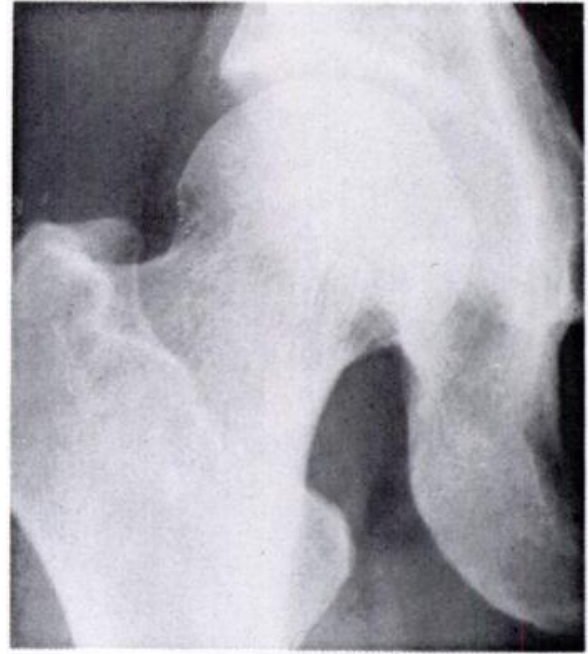

Fig. 7

Case 1. Figure 7-Radiograph of the right femoral head in a patient with idiopathic avascular necrosis of the left femoral head diagnosed two years previously. No symptoms were present but avascular necrosis was suspected on the basis of osteomyelography. Figure 8-Low-power photomicrograph of section of the femoral head biopsy specimen. Repairing granulation tissue and appositional new bone formation occurring after one episode of infarction is present at 1 and 4 , necrosis without evidence of repair at 2 , and degenerative changes in the repairing tissue at 3. Figure 9Photomicrograph of representative field in area 3 showing degenerative change of repairing granulation tissue $(\times 125)$.

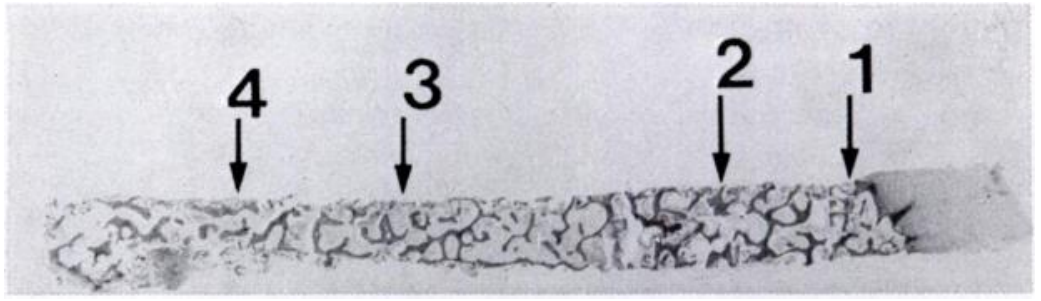

Fig. 8

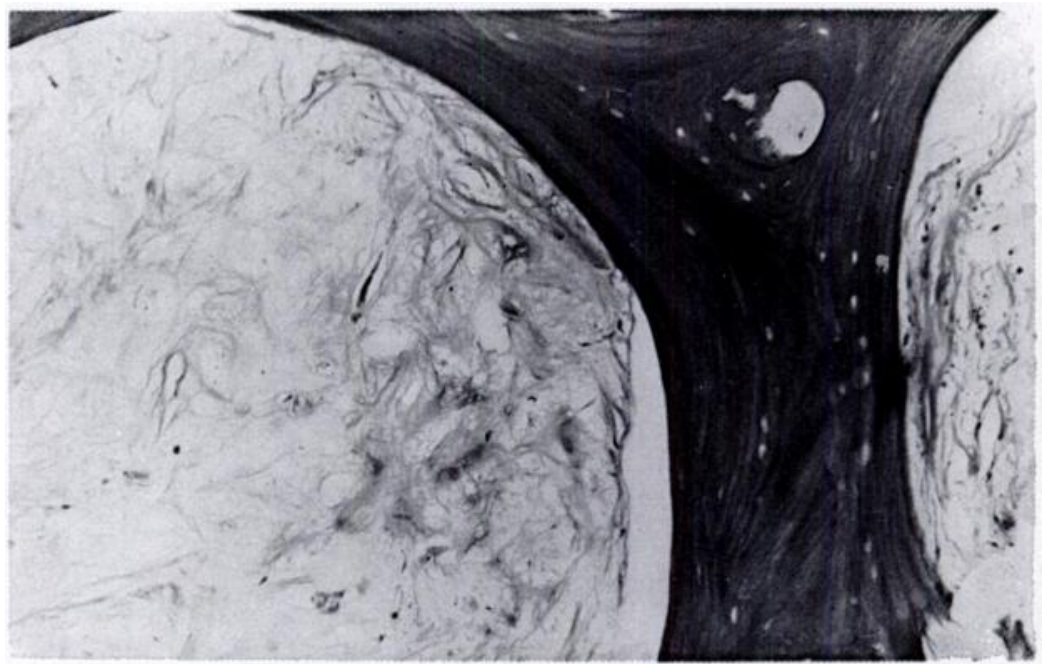

Fig. 9 


\section{RESULTS}

Types of recurrent necrosis. We observed two types of recurrent necrosis. Type I showed necrosis of young fibrous tissue of high osteogenic activity with or without the woven bone of repair. Type II involved the advancing edge of mature granulation tissue without osteogenic activity. In the early stages Type I changes were usually present extensively, whereas in the later stages either a mixture of Type I and Type II necrosis or Type II only was seen and the distribution of Type II was sometimes patchy. In some advanced cases, a necrotic portion of subchondral bone had become completely separated from the remainder of the femoral head.

Table I. Relation between radiological stage and type of recurrent necrosis in forty femoral heads with idiopathic avascular necrosis

\begin{tabular}{|c|cccc|c|}
\hline \multirow{2}{*}{$\begin{array}{c}\text { Radiological } \\
\text { stage }\end{array}$} & \multicolumn{4}{|c|}{$\begin{array}{c}\text { Histological type of } \\
\text { recurrent necrosis }\end{array}$} & \\
\cline { 2 - 5 } & Absent & I & II & I and II & Total \\
\hline I & 1 & 2 & & & 3 \\
II & 1 & 5 & & & 6 \\
III & 2 & 2 & 1 & 3 & 8 \\
IV & 3 & 5 & 6 & 9 & 23 \\
\hline Total & 7 & 14 & 7 & 12 & 40 \\
& $(17.5 \%)$ & $(35.0 \%)$ & $(17.5 \%)$ & $30.0 \%)$ & \\
\hline
\end{tabular}

Histological findings in each radiological stage. The histological findings for all the femoral heads were correlated with the radiological stages (Table I). The findings are illustrated by the following cases.

Case 1 (Stage I). A woman aged forty-two years. Since avascular necrosis was suspected on the basis of osteomyelography a needle biopsy was performed, even though the plain radiograph of the right femoral head was almost normal (Fig. 7). The biopsy specimen taken from the femoral head (Fig. 8) showed an area of necrosis without repair, areas in the process of repair after one episode of infarction, and an area in which degenerative changes were present in tissue undergoing repair (Fig. 9).

Case 2 (Stage II). A man aged forty-three years. A radiograph of the left femoral head seven months after the onset of symptoms showed a cystic translucent shadow but only slight evidence of collapse (Fig. 10). A coronal section of the head revealed an extensive area of repair tissue and a defect in the subchondral zone which showed no evidence of regeneration (Fig. 11). The stained section demonstrated an area which had been repaired after one episode of infarction, a central area occupied by dense granulation tissue with foci of dead granulation tissue and new bone (Fig. 12), and a subchondral area containing necrotic original bone trabeculae and bone marrow with no evidence of repair. The findings suggested that a large portion of this femoral head had undergone infarction on two or more occasions.

Case 3 (Stage III). A man aged forty years. Replacement of the left femoral head was carried out one and a half years after the onset of symptoms. The radiograph showed slight collapse and irregular density of the head (Fig. 13). A coronal section of the head revealed that a line of demarcation had been formed (Fig. 14). Within this line the bone and the bone marrow were dead, and histological evidence of recurrent necrosis was present in this necrotic area (Fig. 15), suggesting that infarction had occurred in tissue undergoing repair. Case 4 (Stage III). A man aged fifty-four years. The radiograph showed slightly irregular density and a moderate degree of collapse (Fig. 16). A coronal section of the left femoral head disclosed repairing granulation tissue across the central part of the femoral head (Fig. 17). In one area of this repair tissue many blood vessels were dead (Fig. 18), suggesting that extensive revascularisation had been interrupted by further episodes of infarction.

Case 5 (Stage IV). A man aged forty-seven years. Total hip replacement had been carried out three years after the onset of symptoms. The radiograph showed complete collapse and severe deformity (Fig. 19). A coronal section of the left femoral head showed loss of articular cartilage and a demarcation line formed by mature granulation tissue (Fig. 20). The advancing edge of the granulation tissue showed necrotic changes (Fig. 21), indicating that revascularisation could not progress beyond this point.

\section{DISCUSSION}

There have been numerous papers describing the histology of idiopathic avascular necrosis of the head of the femur (Merle d'Aubigné et al. 1965; Jacqueline and

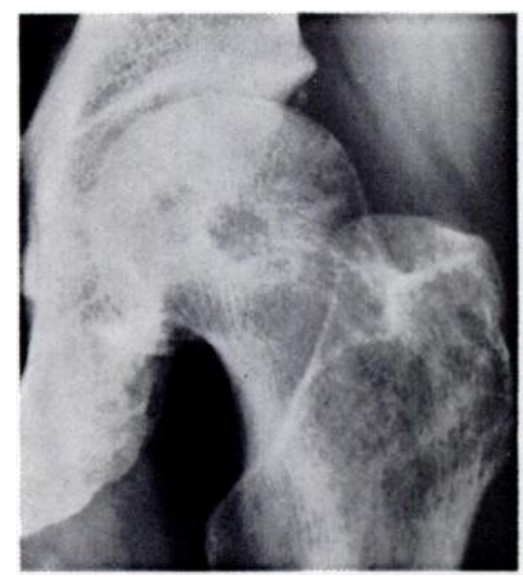

Fig. 10

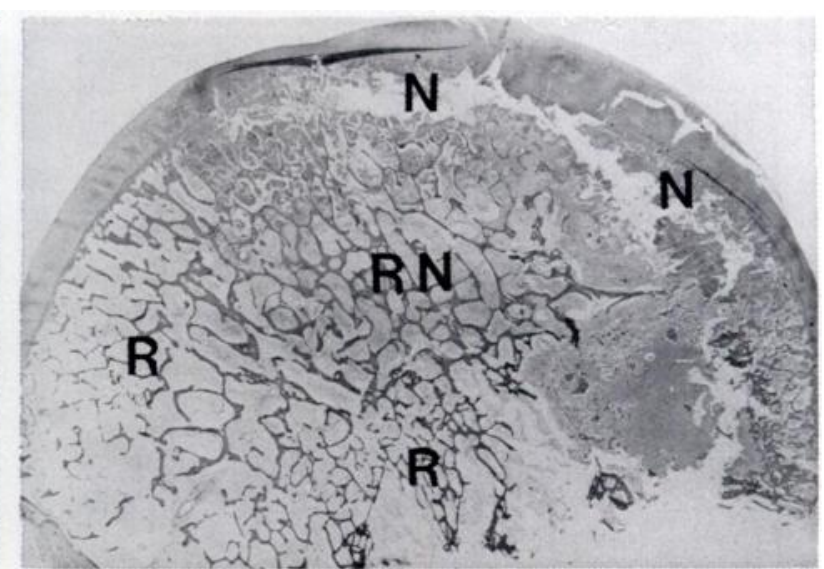

Fig. 11

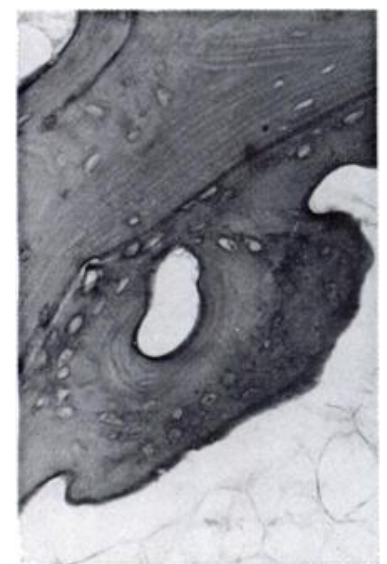

Fig. 12

Case 2. Figure 10-Radiograph showing translucent cystic shadow and slight collapse. Figure 11-Photomicrograph of a coronal section of the femoral head. An extensive area of repairing tissue has spread $(R, R N)$, and a narrow zone of necrosis $(N)$ is present along the subchondral area after a single episode of infarction. Figure 12-Photomicrograph of representative field in area RN, showing dead appositional woven repair bone $(\times 137)$. 


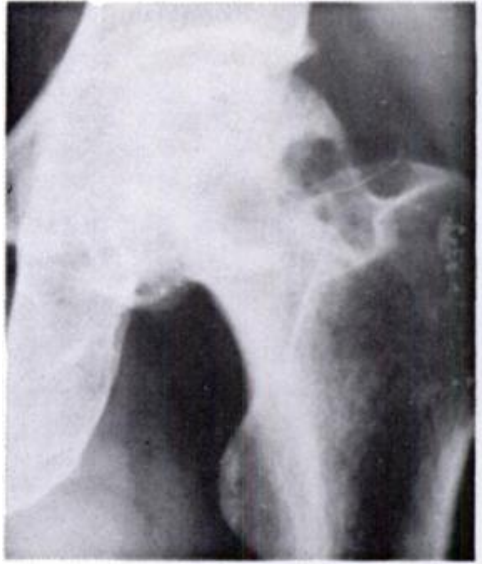

Fig. 13

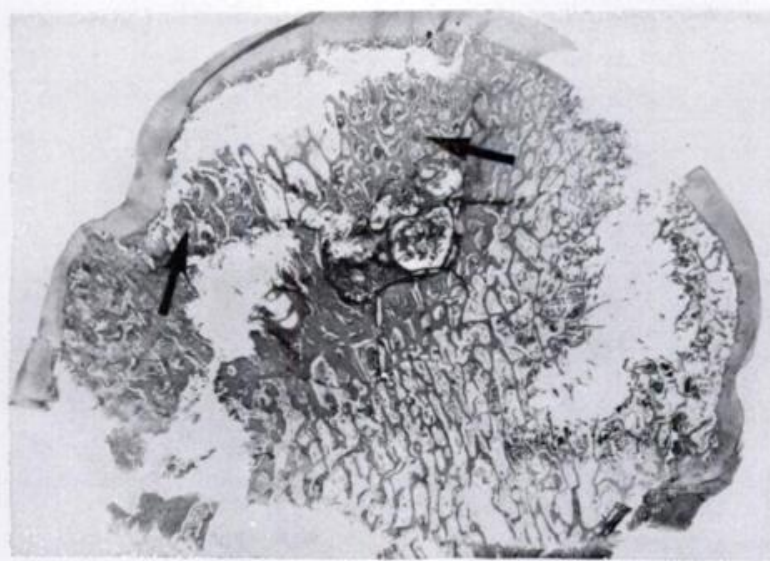

Fig. 14

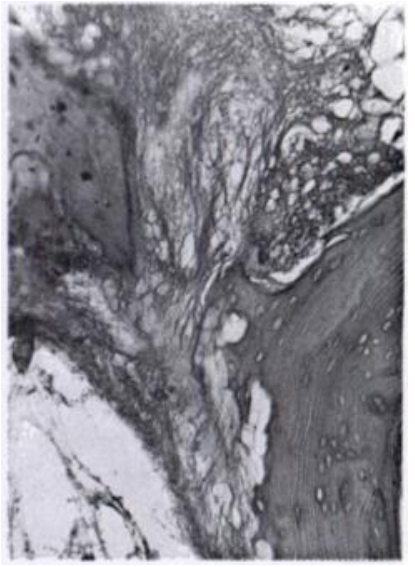

Fig. 15

Case 3. Figure 13-Radiograph showing cystic changes and moderate collapse. Figure 14-Photomicrograph of a coronal section of the femoral head. Total necrosis has occurred within the demarcation line and the histological appearance indicates that some parts (arrowed) have undergone repair at least once. Figure 15-Photomicrograph of part of area indicated by arrows in Figure 14 showing dead woven repair bone and dead granulation tissue $(\times 70)$.

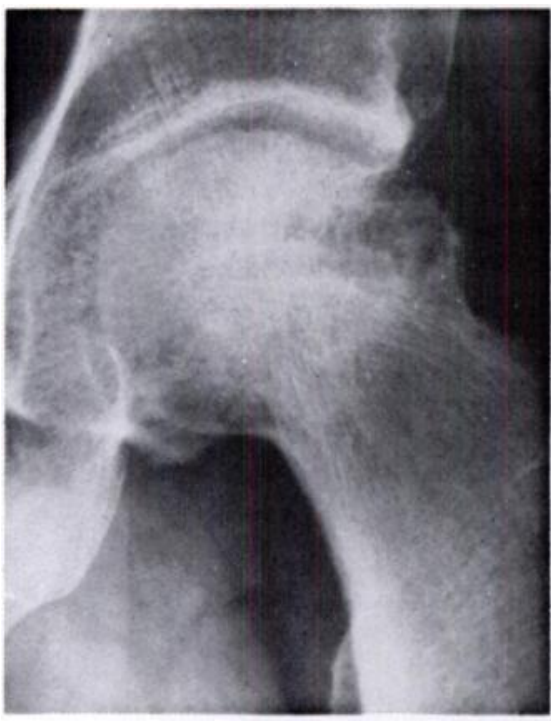

Fig. 16

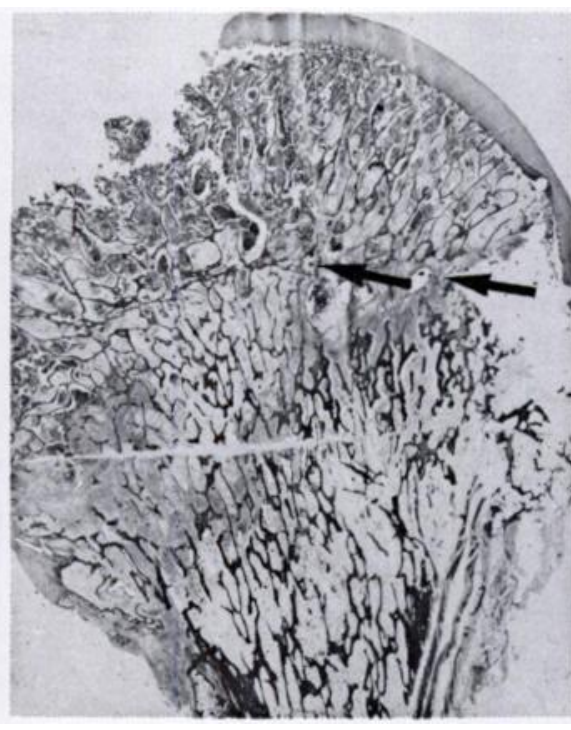

Fig. 17

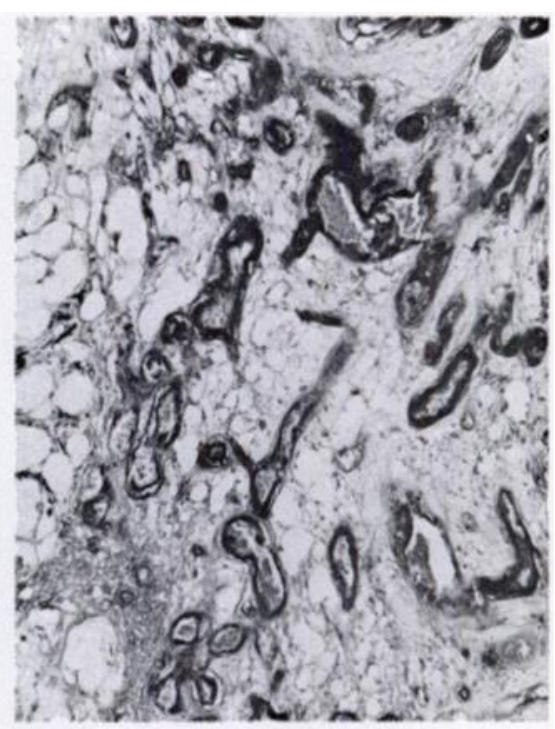

Fig. 18

Case 4. Figure 16-Radiograph showing slightly irregular density and moderate collapse. Figure 17-Photomicrograph of a coronal section of the femoral head. Necrosis is present in the subchondral area and granulation tissue in the central region (arrowed). Figure 18-Abundant dead blood vessels are present in the area indicated by arrows in Figure $17(\times 90)$.

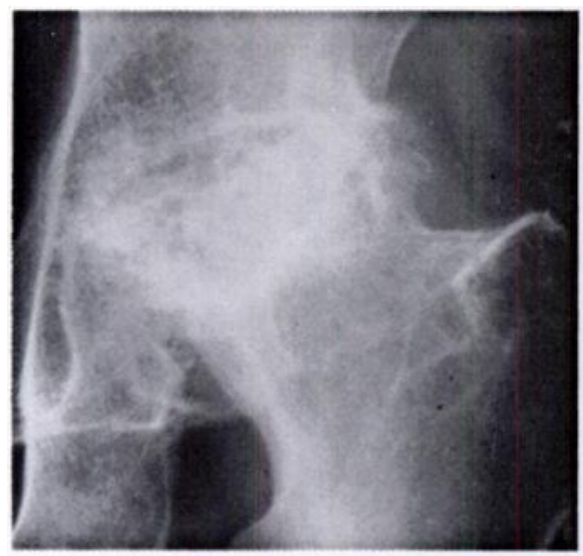

Fig. 19

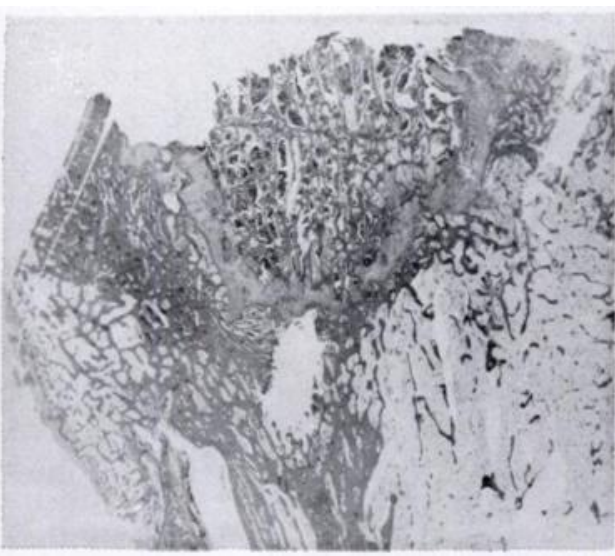

Fig. 20

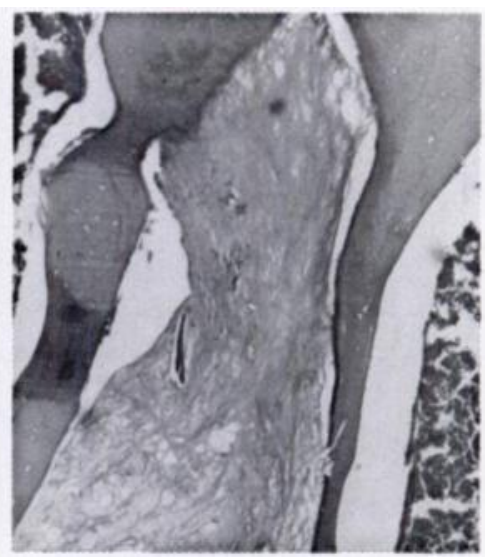

Fig. 21

Case 5. Figure 19-Radiograph showing complete collapse and osteoarthritic change. Figure 20-Photomicrograph of a coronal section of the femoral head showing the subchondral necrotic area demarcated by a line of inactive granulation tissue. Figure $21-$ Photomicrograph of the advancing edge of granulation undergoing degeneration $(\times 30)$. 
Rutishauser 1971; Lagier 1971), but only Springfield and Enneking (1975) postulated that repeated infarcts might occur although they did not discuss the significance of their observation. Catto (1976) suggested that bone necrosis associated with work in compressed air might not be the result of merely a single acute episode of ischaemia.

We have found definite histological evidence of recurrent necrosis occurring in the femoral head in idiopathic avascular necrosis. It may be extensive in the early stage of the condition and young repair tissue may undergo necrosis even when revascularisation has progressed as far as the subchondral zone. These histological findings resemble those seen in the early stage of Perthes' disease (Figs. 22 and 23) which may indicate that the early pathological changes of these two diseases are similar.

In Stage III, when deformity of the femoral head has become obvious, the histological findings of recurrent necrosis are sometimes found in the necrotic subchondral area within the line of demarcation. indicating that repair tissue had once advanced to that level after the first episode of infarction. During the next episode death of this repair tissue had occurred. Complete revascularisation of the femoral head does not appear to occur if two or more episodes of infarction take place.

The mature granulation tissue present at the

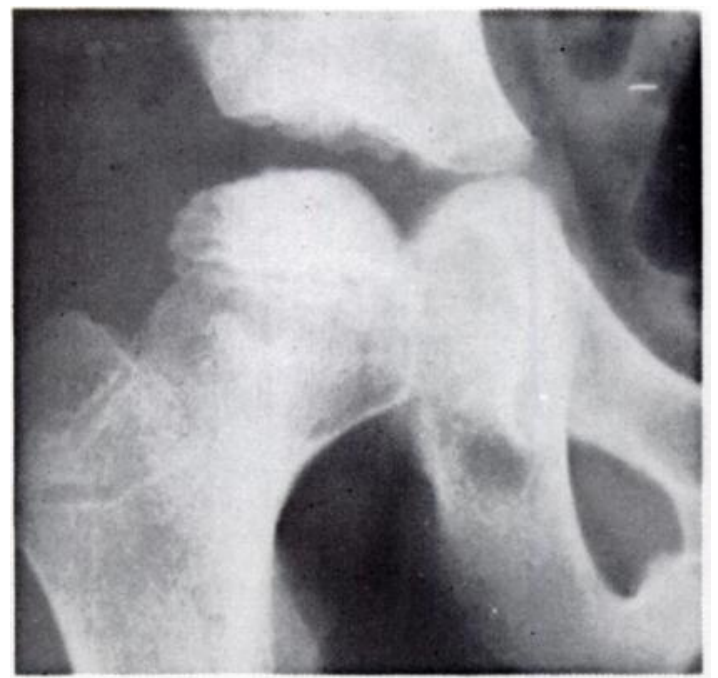

Fig. 22

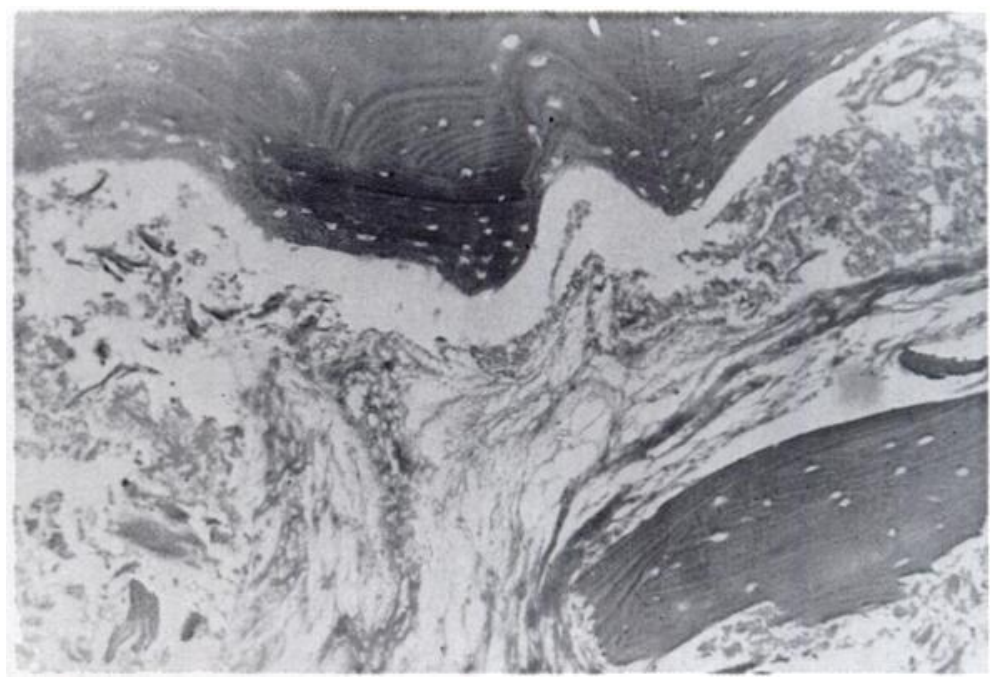

Fig. 23

Figure 22-Radiograph of a patient in the early stage of Perthes' disease. Figure 23-Photomicrograph of section of the femoral head showing death of woven repair bone and granulation tissue ( $\times 115)$.

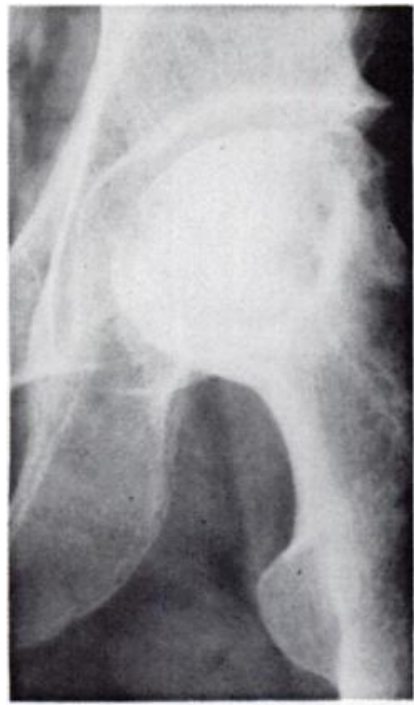

Fig. 24

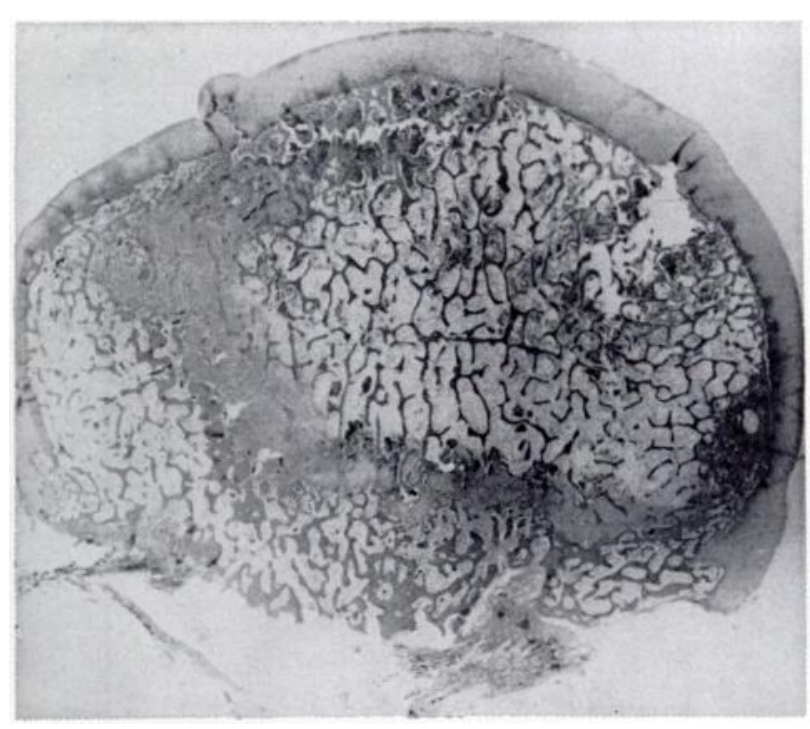

Fig. 25

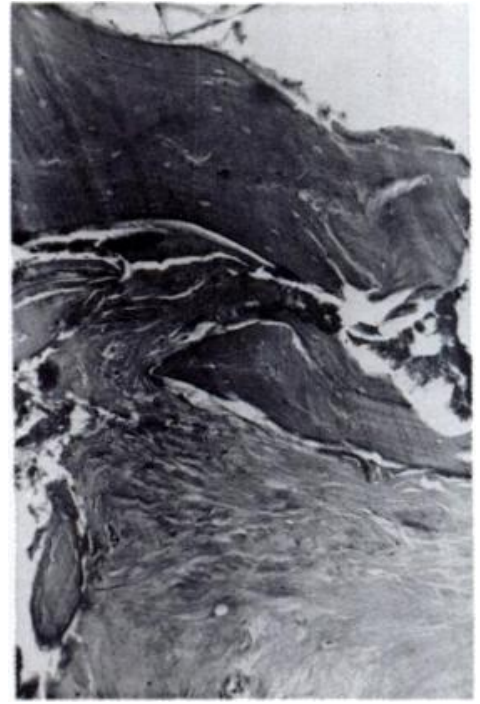

Fig. 26

Figure 24-Radiograph of a patient showing late segmental collapse after fracture of the femoral neck. Figure 25-Photomicrograph of a coronal section of the head showing a demarcation line formed by mature granulation tissue and total necrosis beyond the line. Figure $26-$ Photomicrograph of the advancing edge of granulation tissue showing necrosis of repair tissue $(\times 85)$. 
junction of the necrotic bone with the demarcation line is rich in collagen and has a low level of vascularity and osteogenic activity, in contrast to the young fibrous tissue which entered early after initial infarction. The advancing front of this mature granulation tissue often undergoes necrosis in the later stages.

In Perthes' disease necrosis of the mature granulation tissue without osteogenic activity, present in the femoral capital nucleus, is unusual. This may be an important difference between Perthes' disease and idiopathic avascular necrosis, and may decide whether the involved femoral head can be fully revascularised.

The histological study of avascular necrosis in femoral heads removed because of non-union or late segmental collapse after fracture of the femoral neck has revealed that recurrent necrosis of mature granulation tissue (Type II) is sometimes present (Figs. 24 to 26). The front of the mature granulation tissue may therefore be liable to undergo necrosis in avascular necrosis of the adult femoral head of any type. Recurrent necrosis of young granulation tissue (Type 1 ) occurs widely in the early stages of idiopathic avascular necrosis and in Perthes' disease before collapse is observed, but not after fracture of the femoral neck. The aetiology of recurrent necrosis of young granulation tissue is not known but we suggest that it may be related to that of idiopathic avascular necrosis which may be a chronic condition produced by repeated infarction.

We are grateful to Professor B. Vernon-Roberts for helpful advice and criticism, to Doctors $\mathbf{H}$. Hamada, T. Takase and $\mathbf{H}$. Senrui for providing clinical records, radiographs and histological specimens, and to Miss T. Yamato for typing the manuscript.

This study was supported by a Research Grant from the Intractable Disease Division, Public Health Bureau, Ministry of Health and Welfare, Japan.

\section{REFERENCES}

Catto, M. (1976) Pathology of aseptic bone necrosis. In Aseptic Necrosis of Bone, pp. 3-100. Edited by J. K. Davidson. Amsterdam: Excerpta Medica.

Inoue, A., Freeman, M. A. R., Vernon-Roberts, B., and Mizuno, S. (1976) The pathogenesis of Perthes' disease. Journal of Bone and Joint Surgery, 58-B, 453-461.

Jacqueline, F., and Rutishauser, E. (1971) Idiopathic necrosis of the femoral head (anatomo-pathological study). In Idioputhic Ischemic Necrosis of the Femoral Head in Adults, pp. 34-38. Edited by W. M. Zinn. Stuttgart: Georg Thieme.

Lagier, R. (1971) Idiopathic aseptic necrosis of the femoral head-an anatomo-pathological concept. In Idiopathic Ischemic Necrosis of the Femoral Head in Adults, pp. 49-67. Edited by W. M. Zinn. Stuttgart: Georg Thieme.

Matumoto, Y., and Mizuno, S. (1966) Rate of the blood flow in the femoral head. Medical Journal of Osaka University. 16, $431-463$.

Merle d'Aubigné, R., Postel, M., Mazabraud, A., Massias, P., and Gueguen, J. (1965) Idiopathic necrosis of the femoral head in adults. Journal of Bone and Joint Surgery, 47-B, 612-633.

Springfield, D. S., and Enneking, W. F. (1975) Role of bone grafting in idiopathic aseptic necrosis of the femoral head. In The Hip (Proceedings of the Third Open Scientific Meeting of the Hip Society, 1975), pp. 3-18. St Louis: C. V. Mosby Co. 